Categoria

Trabalho Acadêmico\Resumo Expandido

Titulo do Trabalho

\title{
OCORRÊNCIA DE DÍPTEROS MUSCÓIDES (FANNIDAE) NO MUNICÍPIO DE TEODORO SAMPAIO, SÃO PAULO
}

Nome do Autor (a) Principal

Giovanni Enrico Theotonio

Nome (s) do Coautor (a) (s)

\section{Leonice Seolin Dias}

Nome (s) do Orientador (a) (s)

Instituição ou Empresa

Universidade Estadual Paulista (UNESP) de Presidente Prudente, SP

Instituição (s) de Fomento

Biota/FAPESP

E-mail de contato

giovannienrico@live.com

Palavras-chave

Fanniidae. Bioindicadores. Morro do Diabo

\section{INTRODUÇÃO}

Os Fanniidae pertencem a uma pequena família Díptera encontrada em quase todas as regiões biogeográficas do mundo, com aproximadamente 285 espécies registradas no mundo (CARVALHO et al., 2003).

A maioria dos adultos desta família é encontrada em ambientes florestais. Os machos apresentam um comportamento de ficar pairando no à espera de alimento e as 
fêmeas geralmente são encontradas na vegetação e em resíduos orgânicos existentes no solo. As larvas são saprófagas e ocorrem em todos os tipos de matéria orgânica animal e vegetal em decomposição e também em fezes; algumas se criam em fungos, outras em ninhos de pássaros e tocas de mamíferos (CHILLCOTT, 1961; HOLLOWAY, 1985 MARCHIORI; PRADO 1999).

Algumas espécies de fanídeos estão intimamente associadas ao homem e são mais conhecidas por sua predileção por habitações humanas. Outras espécies ocorrem no ambiente peridomiciliar e se alimentam de fezes e matéria orgânica em decomposição, embora tenham pouca importância como vetores mecânicos de patógenos que ocorrem em fezes (GUIMARÃES; PAPAVERO, 1999).

\section{OBJETIVO GERAL}

O objetivo deste trabalho é de verificar a ocorrência de dípteros muscóides (Fanniidae) em quatro ambientes de Teodoro Sampaio, SP (Parque Estadual do Morro do Diabo; Assentamento Rural; área de cultivo da cana de açúcar e região urbana).

\section{OBJETIVO ESPECÍFICO}

Compreender a distribuição temporal desses insetos durante o período de um ano, relacionando assim a incidência das moscas com a sazonalidade climática da área de estudos escolhida.

\section{METODOLOGIA}

O presente estudo está sendo realizado município de Teodoro Sampaio, SP, localizado a $22^{\circ} 53^{\prime} 25^{\prime \prime}$ 'S e a $52^{\circ} 16^{\prime} 75^{\prime \prime} \mathrm{W}$, distante $112 \mathrm{~km}$ de Presidente Prudente e $672 \mathrm{~km}$ da capital São Paulo. O município encontra-se no extremo oeste do Estado de São Paulo.

Para a captura dos insetos foi escolhido um total de 20 pontos, sendo cinco para cada ambiente, que foram determinados com base em um trabalho prévio, da seguinte maneira: No Parque Estadual do Morro do Diabo, os pontos de instalação das armadilhas para a captura dos insetos foram demarcados, às margens da rodovia, alocando a 


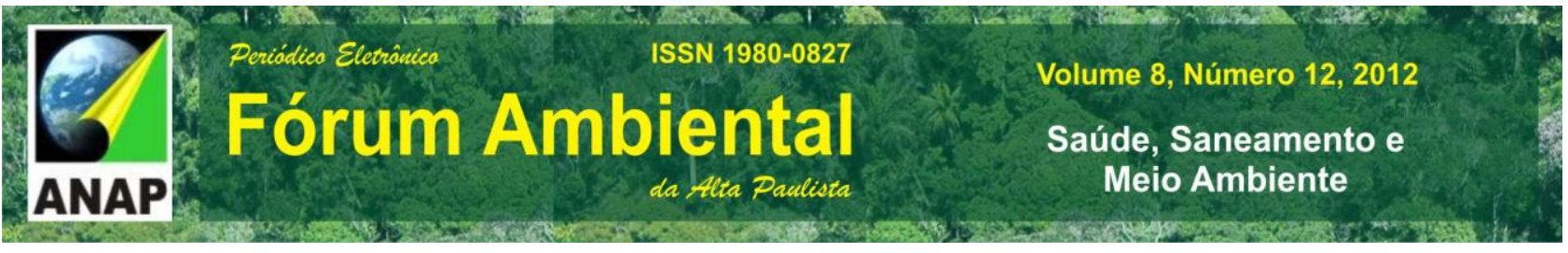

primeira armadilha da rodovia a um quilômetro após o início do parque; e a quinta a um quilômetro antes do término da unidade de conservação. Para as outras três armadilhas, o percurso foi dividido em três partes de comprimentos iguais.

$\mathrm{Na}$ área de monocultura da cana-de-açúcar, os pontos foram escolhidos com os seguintes critérios: em um corredor no meio de um canavial, a $200 \mathrm{~m}$ das margens da rodovia, instalou-se a primeira armadilha e a quinta a $200 \mathrm{~m}$ antes do término do corredor, do lado esquerdo do corredor. Para as três outras, o percurso foi dividido em três partes de comprimentos iguais, sendo duas armadilhas do lado do esquerdo e uma do lado direito do corredor o sentido da entrada.

No assentamento de Ribeirão Bonito, em área contígua ao Parque Estadual do Morro do Diabo, as armadilhas foram distribuídas em cinco lotes, nos quais as residências fossem sombreadas por algum tipo de espécie arbórea de pequeno a grande porte (ornamentais ou frutíferas) e criação de animais domésticos como: porcos, aves, cães, entre outros.

$\mathrm{Na}$ área urbana de Teodoro Sampaio, as armadilhas foram alocadas em residências sombreadas por algum tipo de espécie arbórea de pequeno a grande porte (ornamentais ou frutíferas) e criação de animais domésticos. A figura 1 mostra os pontos de capturas das moscas.

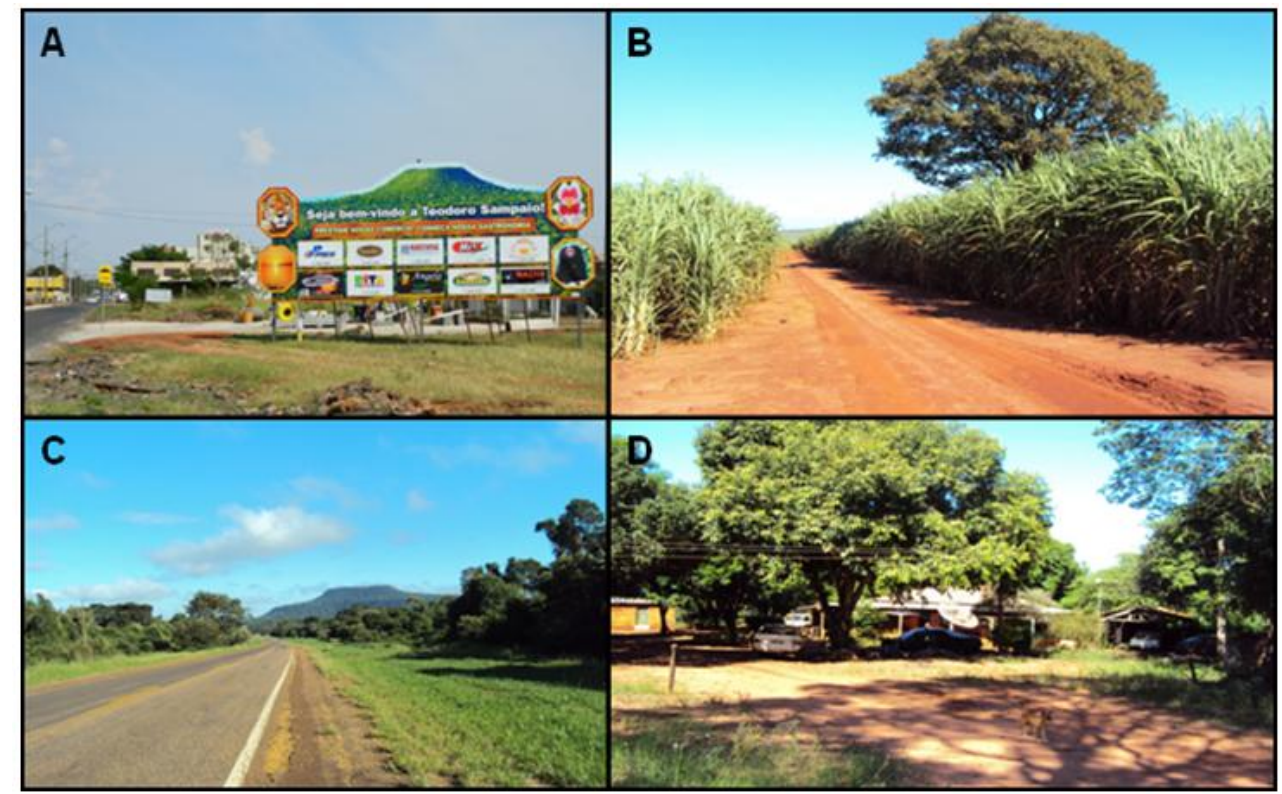

Figura 1. A) Vista parcial da entrada de Teodoro Sampaio, SP; B) Área do canavial de instalação das armadilhas para coletas de moscas; C) Vista parcial do Parque Estadual Morro do Diabo; D) Exemplo de residência típica de uma família do assentamento. Fonte: SEOLIN DIAS (abr, 2012). 


\section{Captura das moscas}

Os espécimes serão capturados, em cada ambiente de coleta, por armadilhas constituídas de garrafas "PET - 2L", adaptando-se a metodologia descrita por Ferreira (1978) e modificadas por Otsuka (2008), e com a utilização de dois diferentes tipos de iscas: aproximadamente $50 \mathrm{~g}$ de fígado bovino e $50 \mathrm{~g}$ de peixe.

As capturas foram realizadas durante dois dias consecutivos, no início, meio e fim de cada estação, totalizando seis coletas, em um período de seis meses, de março a setembro de 2012. As coletas dos insetos, em todos os locais de monitoramento, foram efetuadas nos mesmos dias.

As armadilhas foram instaladas em árvores a uma altura de 1,0 a 1,70 $\mathrm{m}$ do solo, durante 48 horas, quando foram removidas para o Laboratório Biogeografia e Geografia da Saúde da UNESP, Presidente Prudente, SP.

As moscas capturadas foram identificadas com o auxílio de microscópio estereoscópio por meio de chaves taxonômicas específicas para cada família (ALBUQUERQUE et al, 1981; CARVALHO; MOURA; RIBEIRO, 2002; CARVALHO; KOURI, 2002; MELLO, 2003).

\section{RESULTADOS E DISCUSSÃO}

Foi capturado um total de 820 insetos dípteros, sendo 57 (7\%) no assentamento Ribeirão Bonito, 147 (17,9\%) na área do canavial, 426 (51,9\%) no Parque Estadual e 190 $(23,2 \%)$ na área urbana (Figura 2). 


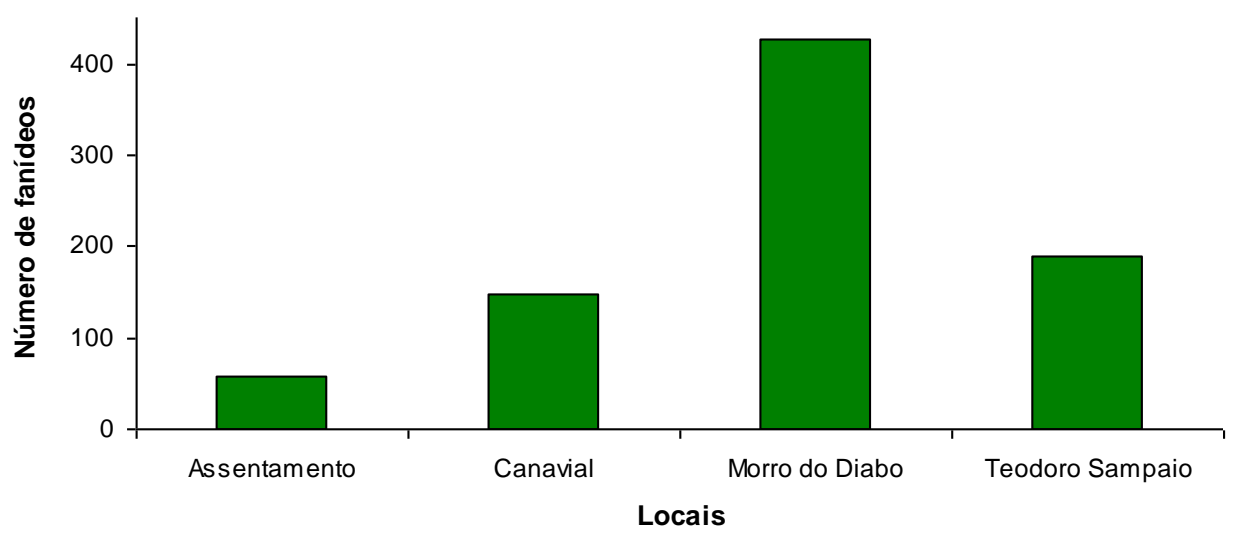

Figura 2. Total de moscas da família fanniidae capturadas, nos quatros locais de observação, no município de Teodoro Sampaio - SP, no período de março a setembro de 2012.

Os resultados do presente estudo apontam para uma maior abundância de fanídeos no parque estadual. Possivelmente, pelo fato da maioria dos adultos desta família habitar áreas de florestas e, além disso, como as armadilhas foram alocadas às margens da rodovia, supõe-se a presença de material orgânico em decomposição constituído pelos cadáveres de animais mortos por atropelamento ao longo do trecho viário que corta o parque.

Outro dado que merece ser considerado, é a presença desses insetos em ambientes habitados pela população humana. Tanto na cidade como nos assentamentos foi possível a captura de moscas fanídeos, o que revela a presença de resíduos orgânicos nesses locais. Dessa forma, a captura dessas moscas em ambientes antrópicos revela 0 impacto ambiental gerado pela produção de lixo pela sociedade, com possíveis riscos de contaminação do ambiente e a transmissão de patógenos, uma vez que os dípteros muscoídes ser vetores mecânicos de agentes patógenos, como parasitos, fungos e bactérias.

\section{CONSIDERAÇÕES FINAIS}

Observou-se uma maior captura de Fanniidae no Parque Estadual Morro do Diabo, possivelmente pelo fato da maioria dos adultos desta família habitar áreas de florestas. Portanto, até o presente momento, fica claro que a ocorrência das moscas 
desta família está fortemente relacionada com o meio natural, menos afetado pelas relações sociais e de produção.

Em contrapartida, observa-se que a quantidade de moscas capturadas na área urbana ainda supera a quantidade de moscas capturadas no assentamento e no canavial, o que demonstra ainda forte dependência dessa família em relação aos materiais orgânicos produzidos pelo homem.

\section{REFERÊNCIAS}

ALBUQUERQUE, D. O.; PAMPLONA, D; C. CARVALHO, C. J. B. Contribuição ao conhecimento dos Fannia R. D., 1830 da região neotropical (Díptera, Fanniidae). Arquivos do Museu Nacional, v. 56, p. 9-34, 1981.

CARVALHO, C. J. B.; MOURA, O. M.; RIBEIRO, P. B. Chave para adultos de dípteros (Muscidae, Fannidae, Anthomyiidae) associados ao ambiente humano no Brasil. Revista Brasileira de Entomologia, v. 46, n. 2; p. 107-114, 2002.

CARVALHO, C. J. B.; PONT, A.C.; COURI, M. S.; PAMPLONA, D. A Catalogue of the Fanniidae and Muscidae (Diptera) of the Neotropical, Region Zootaxa, p. 219: 32, 2003.

COURI, S. M; CARVALHO, C. J. B. Catálogo das espécies de Fanniidae do estado do Rio de Janeiro (Brasil). Biota Neotropica, v. 5, n. 2, 2005.

CHILLCOTT, J. G. A Revision of the Nearctic Species of Fanniinae (Diptera: Muscidae). Canadian Entomologist., v. 92, n. 4, p. 295, 1961.

FERREIRA, M. J. M. Sinantropia de dípteros muscóideos de Curitiba, Paraná. I. Calliphoridae. Revista Brasileira de Biologia, v. 38, p. 445-454, 1978.

GUIMARÃES, J. H.; PAPAVERO, N. Myiasis in man and animals in the Neotropical Region; bibliographic database. Plêiade/FAPESP, São Paulo, p.1-308, 1999.

HOLLOWAY, B.A. 1985. Larvae of New Zealand Fanniidae (Diptera: Calyptrata). New Zealand Journal Zoology, v. 11, p. 239-257, 1985.

MARCHIORI, C. H.; PRADO, A. P. Tabelas de vida de Fannia pusio (Wied.) (Diptera: Fanniidae). Anais da Sociedade Entomológica do Brasil, v. 28, n. 3, p. 557-563, 1999.

OTSUKA, H. Sinantropia e sazonalidade de moscas varejeiras (Diptera: Calliphoridadae) no sudeste do Brasil: visões ecológica, médica, veterinária e forense. Trabalho de Conclusão de Curso (Graduação em Ciências biológicas). Universidade Estadual Paulista (UNESP), Botucatu, SP. 